\title{
Caracterização genotípica de Staphylococcus aureus resistentes à meticilina isolados de tetos e leite bovino
}

\author{
Laura Francielle Ferreira Borges ${ }^{1 *}$; Cintya Neves de Souza ${ }^{2}$; Ester Dias Xavier ${ }^{3}$; Edmara Andrade Macedo \\ Cruz $^{4}$; Alessandra Rejane Ericsson de Oliveira Xavier5; Demerson Arruda Sanglard ${ }^{6}$; Geziella Aurea Aparecida \\ Damasceno Souza $^{7}$; Carolina Magalhães Caires Carvalho ${ }^{8}$
}

DOI: https://doi.org/10.35699/2447-6218.2020.25185

\begin{abstract}
Resumo:
O presente estudo teve como objetivo verificar a presença dos genes mecA, mec ${ }_{\mathrm{LGA} 251}$, blaZ em isolados de $S$. aureus resistente a antibióticos beta-lactâmicos, provenientes de amostras de vacas diagnosticadas com mastite subclínica de rebanhos do norte de Minas Gerais. Isolados previamente identificados através da detecção do gene femA e MALDI-TOF MS e resistentes a antibióticos do grupo beta-lactâmicos foram utilizados. Os isolados foram submetidos à extração de DNA e para o rastreamento dos genes de resistência utilizou se a técnica de PCR. Embora fenotipicamente resistente a oxacilina e cefoxitina nenhuma das linhagens apresentou resultado positivo para os genes mecA e mecA $\mathrm{LGA}_{\mathrm{LG1}}$ nos ensaios efetuados, a ausência destes não descarta a possibilidade da presença de outros genes de resistências nas propriedades rurais em estudo. Porém, a presença do gene blaZ foi verificada em $4(12,90 \%)$ dos isolados em estudo. Os resultados destacam a necessidade do monitoramento e adoção de medidas de controle que evitem à disseminação desses genes que representam grande risco a saúde pública.
\end{abstract}

Palavras chaves: Genes bacterianos. Mastite bovina. Saúde pública.

\section{Genotypic characterization of methicillin-resistant Staphylococcus aureus isolated from teats and bovine milk}

\begin{abstract}
The present study aimed to verify the presence of the mecA and mecA ${ }_{\text {LGA251 }}$ genes and blaZ in isolates of $S$. aureus previously identified and resistant to beta-lactams antibiotics, from samples of cows diagnosed with subclinical mastitis on the surface of bovine ceilings herds in north of Minas Gerais. Isolates previously identified through the detection of the femA gene and MALDI-TOF MS and resistant to antibiotics of the beta-lactams group were used. The isolates were subjected to DNA extraction and the screening of resistance genes was performed using the PCR technique. Although phenotypically resistant to oxacillin and cefoxitin, none of the strains showed positive results for
\end{abstract}

1Universidade Federal de Minas Gerais, Instituto de Ciências Agrárias. Montes Claros, MG. Brasil.

https://orcid.org/0000-0002-1854-7077

${ }^{2}$ Universidade Federal de Minas Gerais, Instituto de Ciências Agrárias. Montes Claros, MG. Brasil.

https://orcid.org/0000-0002-3640-8636

${ }^{3}$ Universidade Federal de Minas Gerais, Instituto de Ciências Agrárias. Montes Claros, MG. Brasil. https://orcid.org/0000-0001-8289-3540

${ }^{4}$ Universidade Federal de Minas Gerais, Instituto de Ciências Agrárias. Montes Claros, MG. Brasil.

https://orcid.org/0000-0002-2493-978X

${ }^{5}$ Universidade Estadual de Montes Claros. Montes Claros, MG. Brasil.

https://orcid.org/0000-0001-8558-4196

${ }^{6}$ Universidade Federal de Minas Gerais, Instituto de Ciências Agrárias. Montes Claros, MG. Brasil.

https://orcid.org/0000-0001-6759-9730

${ }^{7}$ Universidade Estadual de Montes Claros. Montes Claros, MG. Brasil

https://orcid.org/0000-0002-7130-3776

${ }^{8}$ Universidade Federal de Minas Gerais, Instituto de Ciências Agrárias. Montes Claros, MG. Brasil. https://orcid.org/0000-0002-3145-0253

*Autor para correspondência: lauraborges4@outlook.com

Recebido para publicação em 05 de setembro de 2020. Aceito para publicação em 23 de novembro de 2020.

e-ISSN: 2447-6218 / ISSN: 2447-6218. Atribuição CC BY. 
the mecA and mecA $\mathrm{A}_{\mathrm{LGA251}}$ genes in the tests performed, their absence does not rule out the possibility of the presence of other resistance genes in the rural properties under study. However, the presence of the blaZ gene was verified in 4 $(12.90 \%)$ of the isolates under study. The results highlight the need for monitoring and adoption of control measures that prevent the spread of these genes that represent a great risk to public health.

Keywords: Bacterial genes. Bovine mastitis. Public health.

\section{Introdução}

A mastite bovina é uma patologia predominante na pecuária leiteira, caracterizada pela inflamação das glândulas mamárias, responsável por grandes perdas econômicas, pela redução da qualidade e produção do leite. (Silva et al., 2013). Um método eficaz e de baixo custo para o controle e prevenção da mastite é o uso de boas práticas durante a ordenha, entretanto, na conduta terapêutica é importante a identificação do patógeno e o monitoramento da resistência aos antimicrobianos nos casos de mastite subclínica (Moritz; Moritz 2016).

O uso inadequado e indiscriminado de antimicrobianos tem promovido a ocorrência de cepas resistentes, prejudicando a eficiência do tratamento, tornando-se um problema de saúde humana e animal (Mendonça et al., 2012); Moritz; Moritz (2016). Diversos microrganismos patogênicos podem causar inflamação no teto do animal, entretanto Staphylococcus aureus (S. aureus) é um dos principais agentes etiológicos causadores da mastite bovina (Silva et al., 2013; Song et al., 2016; Sheet et al., 2019).

A meticilina é um antimicrobiano do grupo beta-lactâmico que normalmente não é utilizado no tratamento da mastite, porém, cepas de $S$. aureus meticilina resistentes (MRSA) têm sido identificadas em fazendas leiteiras (Paterson et al. 2014), tornando-se preocupante em termos de saúde pública, já que são frequentemente identificadas como causadoras de infecções hospitalares, até mesmo nas unidades de terapia intensiva (Rabelo et al., 2014; Cerqueira; Almeida, 2013).

Estudos relatam o isolamento de estafilococos multirresistentes à meticilina em animais, humanos (Siqueira et al., 2017) e em alimentos de origem animal, como carne bovina e suína, frango, leite e outros derivados (Cerqueira; Almeida, 2013). Além disso, o consumo de leite e derivados contaminados pode desencadear a transferência de MRSA para seres humanos (Silva et al., 2018).

O isolamento de MRSA em amostras de leite é realizado através de provas fenotípicas pelo plaqueamento em meios de cultura seletivos como ágar base acrescido de sangue ovino, ágar MRSA e pelo ágar sal manitol (Silva et al., 2018). A identificação fenotípica de resistência a meticilina pode ser realizada por meio de testes de suscetibilidade aos antimicrobianos oxacilina e cefoxitina (CLSI, 2018). A nível molecular a resistência a meticilina pode ser detectada através da técnica de Reação em Cadeira de Polimerase (PCR) por meio da amplificação dos genes mecA e mecC (Silva et al., 2018), recentemente foi detectado um homólogo do mecA, o mec $A_{\mathrm{LGA} 251}$ (García-Álvarez et al., 2011).

A resistência estafilocócica aos antibióticos beta-lactâmicos é resultante de dois mecanismos distintos: produção da enzima extracelular beta-lactamase, codificada pelo gene blaZ ou pela produção de PBP2a ou PBP2, uma proteína ligante de penicilina de baixa afinidade, codificada pelo gene mecA e seu homólogomec $\mathrm{A}_{\mathrm{LGA251}}$ (García-Álvarez et al., 2011; Mendonça, et al., 2012).

O aumento nas taxas de ocorrências, as mudanças no padrão epidemiológico das cepas MRSA e as dificuldades no tratamento das infecções ocasionadas por essa bactéria têm colocado a mesma em destaque dentre os microrganismos de notoriedade médica e de desafio á saúde pública mundial (Sales; Mendes, 2012). Visto que linhagens de MRSA produzem diversas toxinas associadas à intoxicação alimentar em humanos (Siqueira et al., 2017), assim é indispensável à realização de novos estudos para compreender a transmissão entre as espécies e o perigo que cada uma impõem em relação à saúde pública, principalmente estudos de distribuição molecular dos isolados (Pantosti, 2012).

Considerando este cenário, o presente estudo teve como objetivo detectar a presença dos genes mecA, $m_{e c} \mathrm{~A}_{\mathrm{LGA251}}$ e blaZ por meio da reação em cadeia da polimerase (PCR), a partir de DNA genômico extraído de cepas de Staphylococcus aureus provenientes de amostras de leite mastítico de diferentes propriedades do norte de Minas Gerais.

\section{Materiais e métodos}

\section{Aprovação ética}

Este trabalho foi realizado dentro dos princípios éticos aprovados pela Comissão de Ética e Experimentação Animal da Universidade Federal de Minas Gerais (UFMG) sob o protocolo número 145 de 2013.

Isolados bacterianos e perfil de sensibilidade a antimicrobianos beta-lactâmicos 
Caracterização genotípica de Staphylococcus aureus resistentes à meticilina isolados de tetos e leite bovino

Trinta e um isolados de $S$. aureus da bacterioteca do laboratório de Sanidade Animal do Instituto de Ciências Agrárias da Universidade Federal de Minas Gerais, registrados no Sistema Nacional de Gestão do Patrimônio Genético e do Conhecimento Associado (SisGen), cadastro AD13F8D, foram utilizados neste estudo. As amostras de $S$. aureus foram isoladas em nove propriedades rurais do norte de Minas Gerais, sendo estes isolados 27 do leite de vacas diagnosticadas com mastite subclínica e 4 da superfície de teto bovino. A coleta do leite nessas propriedades foi realizada em julho de 2018, e janeiro a abril de 2016 e julho de 2019.

Os isolados foram previamente identificados por meio da detecção do gene femA, marcador especifico de espécie para $S$. aureus meticilina resistente, conforme descrito por (Xavier et al., 2017a) e MALDI-TOF MS (Assis et al., 2017) e testados quanto ao perfil de sensibilidade a antibióticos do grupo beta-lactâmicos pelo método disco de difusão conforme protocolo do Clinical and Laboratory Standards Institute (CLSI, 2018). Foram testados os antimicrobianos oxacilina $(1 \mu \mathrm{g})$, cefoxitina (30 $\mu \mathrm{g})$, penicilina $(10 \mu \mathrm{g})$, amoxicilina $(10 \mu \mathrm{g})$, cefoxitina $(30 \mu \mathrm{g})$ e ampicilina $(10 \mu \mathrm{g})$ da Laborclin. Como controle positivo foi utilizado uma cepa padrão de $S$. aureus ATCC 25923.

\section{Extração DNA e PCR do gene 16S rDNA}

Os isolados criopreservados foram reativados em caldo BHI (Kasvi) e incubados a $37^{\circ} \mathrm{C}$ por 24 horas. $\mathrm{O}$ DNA genômico foi extraído pelo método de digestão por proteinase $\mathrm{K}$, seguidas por fenol-clorofórmio de acordo com metodologia descrita por Gu et al. (2005). A integridade do DNA foi verificada por eletroforese em gel de agarose $1,2 \%$. O material obtido foi empregue nas reações de PCR neste estudo.

A amplificação do gene 16S rDNA universal bacteriano foi verificado por PCR, utilizando os primers
DG74 5'AGGAGGTGATCCAACCGCA3' e RW01 5'AACTGGAGGAAGGTGGGGAT3', segundo metodologia descrita por Xavier et al. (2017b). As reações foram efetuadas em um mix contendo 2X GoTaq ${ }^{\circledR}$ Green Master Mix(Promega Corporation, EUA), $\mathrm{MgCl} 2$ (2,5 mm), 10 $\mu \mathrm{M}$ de cada primer e $50 \mathrm{ng}$ de DNA bacteriano, totalizando um volume final de reação de $50 \mu \mathrm{L}$. As condições de amplificação foram as seguintes: um ciclo inicial de desnaturação a $94^{\circ} \mathrm{C}$ por 5 minutos, seguido de 35 ciclos de desnaturação a $95^{\circ} \mathrm{C}$ por $30 \mathrm{~s}$, recozimento a $57^{\circ} \mathrm{C}$ por 30 s, extensão a $72^{\circ} \mathrm{C}$ por 45 se uma extensão final de 10 min.Os amplicons foram visualizados em gel de agarose a $1,5 \%$ corados com gel red e fotodocumentados.

Os primers utilizados neste estudo foram sintetizados pela Integrad DNA Technology, EUA.

\section{Análise PCR para a detecção dos genes $\operatorname{mec} \mathrm{A}, \operatorname{mec} A_{\mathrm{LGA} 251}$ e blaZ}

A técnica de PCR também foi utilizada para determinação da presença dos genes mecA, mecA $\mathrm{LGA}_{\mathrm{L} 251 \mathrm{~A}} \mathrm{e}$ blaZ.

Trinta e um isolados foram utilizados no rastreamento dos genes mecA e mecA $\mathrm{LGA}_{\mathrm{L} 251}$ e blaZ. Os iniciadores, programas de amplificação e os tamanhos dos fragmentos esperados na amplificação pela reação estão descritos na Tabela 1 . As reações foram realizadas em um mix contendo 1x Tampão da Taq do kit Kappa PCR, 3,5 $\mu \mathrm{L}$ de $\mathrm{MgCl}_{2}(2,5 \mathrm{~mm}), 2,5 \mu \mathrm{L}$ de Tris, deoxinucleotídeos $(1 \mu \mathrm{M})$, $0,1 \mu \mathrm{l}$ de Taq Polimerase (Kappa0,5U), 1,0 $\mu \mathrm{L}$ de cada primer e $3 \mu \mathrm{L}(50 \mathrm{ng} / \mu \mathrm{L})$ de DNA bacteriano, com um volume final de reação de $25 \mu \mathrm{L}$.As reações foram realizadas em Thermal Cycler T100 ${ }^{\mathrm{TM}}$ (Bio - RadLaboratories, Alemanha). As condições para realização da PCR foram descritas de acordo com os autores citados na Tabela 1. Os amplicons foram visualizados em gel de agarose a 1,5\% corados com Gel Red e fotodocumentados. Como controle positivo, utilizou-se a cepa padrão $S$. aureus ATCC 43300.

Tabela 1- Primers e condições de amplificação para a detecção dos genes mecA, mecA ${ }_{\mathrm{LGA} 251}$, blaZ em isolados de $S$. aureus de amostras de leite bovino diagnosticados com mastite subclínica.

\begin{tabular}{|c|c|c|c|c|}
\hline Primer & Sequência & Gene & Amplicon & Referência \\
\hline MECA1 & AGTTCTGCAGTACCGGATTTGC & \multirow{2}{*}{ mecA } & \multirow{2}{*}{$533 \mathrm{pb}$} & \multirow{2}{*}{ Dias et al.,(2011). } \\
\hline MECA2 & AAATCGATGGTAAAGGTTGGC & & & \\
\hline MECAL1 & TCACCAGGTTCAAC[Y]CAAAA & \multirow{2}{*}{$\operatorname{mec}_{\mathrm{LGA251}}$} & \multirow{2}{*}{$344 \mathrm{pb}$} & \multirow{2}{*}{$\begin{array}{c}\text { García-Álvarez et } \\
\text { al., (2011). }\end{array}$} \\
\hline MECAL2 & CCTGAATC[W]GCTAATAATATTTC & & & \\
\hline BLAZ1 & TTAAAGTCTTACCGAAAGCAG & \multirow{2}{*}{ blaZ } & \multirow{2}{*}{$377 \mathrm{pb}$} & $\begin{array}{l}\text { Bagcigil et al., } \\
\text { (2012), }\end{array}$ \\
\hline BLAZ2 & TAAGAGATTTGCCTATGCTT & & & $\begin{array}{l}\text { Olsen et al., } \\
\text { (2006); }\end{array}$ \\
\hline
\end{tabular}




\section{Resultados e Discussão}

A partir da PCR da região $16 \mathrm{~S}$ rDNA ribossomal de bactérias, observou-se a amplificação de um fragmento de aproximadamente $370 \mathrm{pb}$, compatível com a região analisada, em todos os isolados utilizados no estudo.
Embora fenotipicamente tenha sido observado que as cepas utilizadas foram resistentes a oxacilina e cefoxitina, a presença dos genes mecA (Figura 1) com fragmento de 533 pb e mecA ${ }_{\mathrm{LGA} 251} 344$ pb não foram verificados nas análises efetuadas. A cepa ATCC 43300 de $S$. aureus utilizada como controle positivo amplificou para ambos os genes nos ensaios realizados.

Figura 1 - Detecção do gene mecA por PCR em $S$. aureus isolados de leite mastítico e da superfície do teto de vacas em propriedades rurais no norte de Minas Gerais

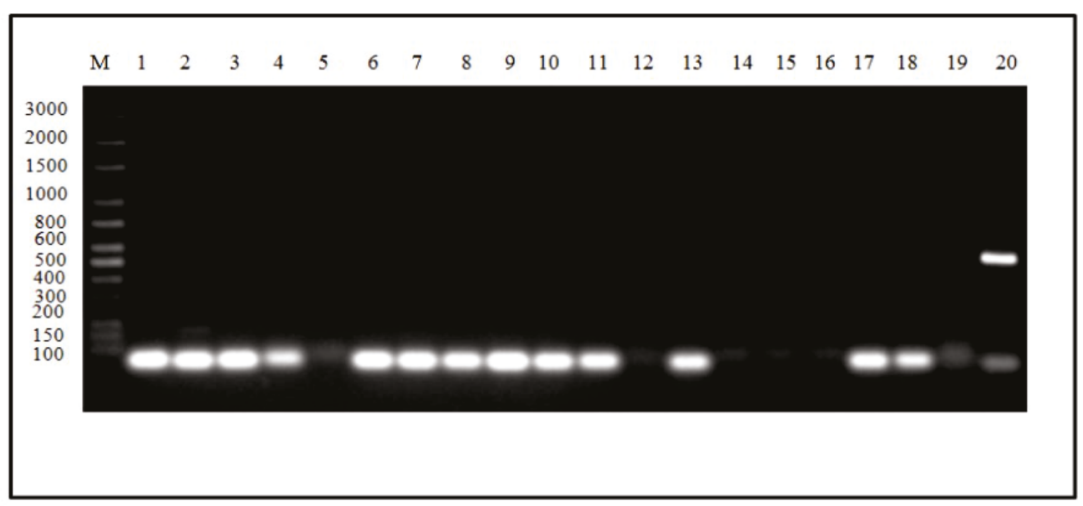

M: Marcador de massa molecular DNA de 100 pares de base (Cellco); Linhas 1 a 10: Isolados leite de vacas diagnosticadas com mastite subclínica. Linhas 11 a 14: Isolados da pele de vacas leiteiras. Linhas 15 a 19:Isolados leite de vacas com mastite subclínica. A linha 20 representa o controle positivo: cepa $S$. aureus ATCC 43300.Gel de agarose a 1,5\%.

Este estudo não identificou a presença dos genes mecA e mecA ${ }_{\mathrm{LGA} 251}$, estes resultados são compatíveis com os descritos por Mendonça et al. (2012), que não observaram a presença do gene mecA em 250 cepas de Staphylococcussp isolados de tetos com mastite subclínica no Brasil , resistentes a meticilina. Os autores relatam que não tem sido observada correlação entre os perfis fenotípicos de resistência e a detecção gênica, sendo necessário investigar os processos de regulagem e transcrição gênica do mecA, bem como do produto dessa expressão, PBP2a e PBP2b proteínas ligantes de penicilina de baixa afinidade, responsáveis pela resistência antimicrobiana.

Sheet et al. (2019), também não observaram a presença do gene mecA em isolados do leite de vacas diagnosticas com mastite na Alemanha,estes isolados foram classificados como $S$. aureus suscetível à meticilina (MSSA). Melo et al., 2014, relatam S. aureus isolados de leite e Staphylococcus coagulase negativo das mãos de ordenhadores fenotipicamente resistentes a oxacilina e negativos para o gene mecA no Rio de Janeiro .Resultados divergentes observados em leite de tetos com masite são descritos na literatura, Diniz et al. (2010), encontraram o gene mecA em 33,78\% dos isolados resistentes a oxacilina, sendo mais frequentemente isolado em $S$. aureus e Staphylococcus coagulase negativa, com índices de $48 \%$ e $32 \%$ respectivamente, em isolados de mastite recorrente em propriedades rurais da região de Uberlândia em Minas Gerais. Qu et al. (2019) verificaram presença de mecA $16 \%$ e gene blaZ em $95 \%$ de isolados de $S$. aureus proveniente de vacas com mastite clínica em fazendas leiteiras em diferentes regiões da China. Dias et al. (2011), avaliaram 200 amostras de leite obtidas de tanques de refrigeração em propriedades rurais da microrregião de Sete Lagoas em Minas Gerais, observando que 11\% das amostras apresentavam o gene mecA.

Os resultados obtidos para o gene mecA $\mathrm{LGA}_{\mathrm{LG1}}$ são semelhantes ao resultado de Souza et al. (2019), que avaliaram a resistência fenotípica e genotípica em $S$. aureus isolados de leite de bovino em fazendas na região norte de Minas Gerais, os autores relatam que os isolados apresentarem resistência fenotípica a pelo menos três antibióticos beta-lactâmicos, mas não identificaram resultado positivo para mecA $A_{\mathrm{LGA} 251}$. No Brasil, nenhum estudo detectou a presença do gene mecA $_{\mathrm{LGA} 251}$, corroborando com os resultados obtidos. Diaz et al. (2016) publicaram estudo de metanálise indicando uma baixa prevalência $(0,009 \%)$ deste gene entre os MRSA, destacando a importância de monitorar a epidemiologia dessa forma variante emergente.O uso generalizado de antibióticos em medicina humana, veterinária e agricultura tem desempenhado papel significativo no surgimento de clones resistentes de MRSA devido à pressão de seleção (Mehndiratta; Bhalla, 2014), agravando este sério problema de saúde pública mundial. O Grupo de Trabalho Internacional sobre Classificação de Elementos Cromossômicos de Cassetes Estafilocócicos (IWG-SCC) (2009) relatam que determinar o mecanismo SCC não é indicado como o único foco na detecção da resistência á meticilina, uma vez que foram descritos outros elementos que não apresentam o gene mecA, mas contêm outros genes que codificam fatores de virulência ou resistência a outros antimicrobiano. 
Caracterização genotípica de Staphylococcus aureus resistentes à meticilina isolados de tetos e leite bovino

O gene blaz foi observado em 4 (12,90\%) dos isolados resistentes a beta-lactâmicos avaliados e na cepa padrão de $S$. aureus ATCC 43300, apresentando um produto de amplificação com tamanho correspondente a $377 \mathrm{pb}$ conforme demonstrado na figura 2 .

Figura 2 - PCR para identificação do gene blaZ sobre as amostras de Staphylococcus aureus isoladas de leite mastítico em propriedades no norte de Minas Gerais.

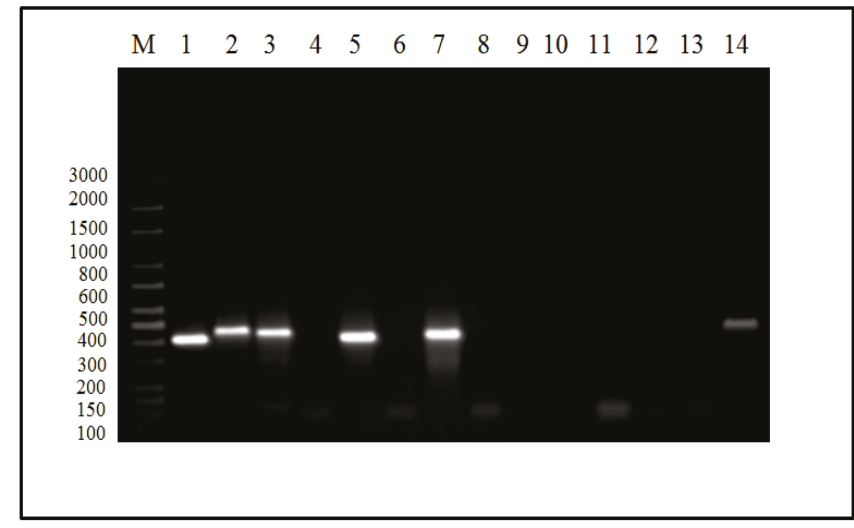

M: Marcador de massa molecular DNA de 100 pares de base (Cellco). A linha 1representa o controle positivo $S$. aureus ATCC 43300. Linhas 2 a 14: $S$. aureus provenientes do leitede vacas diagnosticadas com mastite subclínica Gel de agarose a 1,5\%.

A baixa porcentagem de $S$. aureus positivos para o gene blaZ neste estudo indica que pode haver a presença de outros genes responsáveis pela resistência bacteriana aos antibióticos beta-lactâmicos. Rahi et al. (2020) avaliaram 28 isolados provenientes de amostras de leite cru, incluindo bovinos, ovinos, caprinos, búfalos e camelos de diferentes centros comerciais, os autores encontram uma maior ocorrência do gene blaZ, onde $100 \%$ dos isolados apresentavam o gene. Para Silva et al. (2018), a transmissão de $S$. aureus meticilina resistente (MRSA) por meio do contato de humano com animais ou vice-versa, possibilita a transmissão desse patógeno entre espécies, contribuindo com a variação nas taxas de infecções.

Os resultados obtidos são semelhantes ao de Bissong e Ateba (2020), que identificaram o gene blaZ em $37,7 \%$ dos isolados de amostras de leite pasteurizado e não pasteurizado no noroeste da província da África do Sul. De acordo com Schnitt e Tenhagen (2019), o risco de infecção por MRSA através do consumo de leite aparenta ser baixo, pois geralmente o leite é submetido a tratamento térmico para a comercialização e consumo, porém a prevalência do mesmo deve ser monitorada com cautela, pois estudos sugerem níveis crescentes de resistência. Por outro lado, trabalho desenvolvido por Agnol et al. (2013), foi encontrado percentualde 58,33\% para a presença do gene blaZ em Staphylococcus spp. isolados de rebanho ovino diagnosticado com mastite. O estudo de Olsen et al. (2006), afirmam que as espécies de Staphylococcus presentes no mesmo microambiente podem passar o gene blaZ uma a outra, se os fatores bacterianos forem atendidos.

Ruegg et al. (2015), determinaram a susceptibilidade antimicrobiana de $S$. aureus e Streptococcus spp. de isolados de casos de mastite clinica e a presença de genes de resistência antimicrobiano (blaZ, ermC, tetK e tet $\mathrm{M})$. Os autores relatam que a presença de genes de resistência não foi proporcional a ocorrência de resistência fenotípica, sugerindo uma seleção mais ampla de genes deve ser testada e que mais pesquisas devem ser realizadas para validar os pontos de interrupção da resistência.

Vários genes estão associados á resistência aos beta-lactâmicos que exige uma investigação minuciosa que inclua a detecção de diferentes marcadores genéticos de resistência, tal como o estudo da regulação da expressão gênica do sistema mec, para investigar a compreensão do real valor de sua detecção na predição da resistência aos antimicrobianos beta-lactâmicos, conforme preconizado pelo CLSI (Clinical and Laboratory Standards Institute) (Mendonça et al.,2012). Souza et al. (2019), pressupõe que a epidemiologia molecular, conhecimento aprimorado ligado a base genética da resistência aos antibióticos beta-lactâmicos podem contribuir para afirmação de diretrizes para aprimorar práticas de manejo no tratamento da mastite subclínica e no mapeamento da origem de patógenos resistentes.

\section{Conclusão}

Com este estudo detectou-se a presença do gene blaZ em $12,90 \%$ das cepas de S. aureus resistentes a beta-lactâmicos, os gene mecA e mec $A_{\mathrm{LGA} 251}$ não foram identificados nos isolados em estudo. Entretanto, a ausências destes não descarta a possibilidade da presença de outros genes de resistência nas propriedades em estudo. bem como a possibilidade de veiculação de clones resistentes para humanos. Os resultados salientam a necessidade do monitoramento, adoção de medidas de controle que dificultem a disseminação desses genes e o aumento de pesquisas no rastreamento dos possíveis genes que possam estar relacionados ao mecanismo de 


\section{Referências}

Agnol; A. M. D.; Cavalcante, M. B.; França, C. A.; Costa Krewer, C.; Queiros, A. A.; Costa, M. M.; Bragança, J. F. M.; Girardini, L. K. 2013. Caracterização fenotípica e molecular de isolados de Staphylococcus spp. obtidos de leite de ovelhas do Município de Chapecó-SC. Semina: Ciências Agrárias, 34: 311-321. Disponível em: https://www.redalyc. org/articulo.oa?id $=445744119024$.

Assis, G. B.; Pereira, F. L.; Zegarra, A. U.; Tavares, G. C.; Leal, C. A.; Figueiredo, H. C. 2017. Use of MALDI-TOF mass spectrometry for the fast identification of gram-positive fish pathogens. Frontiers in microbiology, 8: 1492. Doi: https://doi.org/10.1111/jfd.12493.

Bagcigil, A. F; Taponen, S.; Koort, J.; Bengtsson, B.; Myllyniemi, A. L.; Pyörälä, S. 2012. Genetic basis of penicillin resistance of $S$. aureus isolated in bovine mastitis. Acta Veterinaria Scandinavica; 54: 1-7. Doi: https://doi.org/10.1186/1751-0147-54-69.

Bissong, M. E. A.; Ateba, C. N. 2020. Genotypic and Phenotypic Evaluation of Biofilm Production and Antimicrobial Resistance in Staphylococcus aureus Isolated from Milk, North West Province; South Africa. Antibiotics, 9: 156. Doi: https://doi.org/10.3390/antibiotics9040156.

Cerqueira; E. S.; Almeida; R. C. C. Staphylococcus aureus resistente à meticilina (MRSA) em alimentos de origem animal: uma revisão sistemática. 2013. Revista do Instituto Adolfo Lutz. 72: 268-281. Disponível em: https://pdfs.semanticscholar. org/6474/0dd34639cf6c988128a785f47595a68b0182.pdf.

CLSI. Performance Standards for Antimicrobial Susceptibility Testing. 2018. 28th ed. CLSI supplement M100. Wayne, PA: Clinical and Laboratory Standards Institute.

Dias, N. L.; Silva, D. C. B.; Oliveira, D. C. B. S.; Fonseca Júnior, A. A.; Sales, M. L.; Silva, N. 2011. Detecção dos genes de Staphylococcus aureus, enterotoxinas e de resistência à meticilina em leite. Arquivo Brasileiro de Medicina Veterinária e Zootecnia, 63(6): 1547-1552. Doi: https://doi.org/10.1590/S0102-09352011000600036.

Diaz; R.; Ramalheira. E.; Afreixo, V.; Gago, B. 2016. Methicillinresistant Staphylococcus aureus carrying the new mecC gene-a metaanalysis. Diagnostic microbiology and infectious disease, 84: 135-140. Doi: https://doi.org/10.1016/j.diagmicrobio.2015.10.014.

Diniz, C. M.; Melo, R. T. D.; Mendonça, E. P.; Coelho,L. R.; Fonseca, B. B.; Rossi; D. A. 2010. Resistência a oxacilina em Staphylococcus spp isolado de leite mastítico. Revista do Instituto Adolfo Lutz,69: 482-488. Disponível em: http://www.ial.sp.gov.br/ial/revista/rev-inst-adolfolutz.2010694.

García-Álvarez, L.; Holden, M. T.; Lindsay, H.; Webb, C. R.; Brown, D. F.; Curran, M. D.; ... Parkhill, J. 2011. Meticillin-resistant Staphylococcus aureus with a novel mecA homologue in human and bovine populations in the UK and Denmark: a descriptive study. The Lancet infectious diseases, 11: 595-603. Doi: https://doi.org/10.1016/S14733099(11)70126-8.

Gu, J.; Li, H.; Li, M.; Vuong, C.; Otto, M.; Wen, Y.; Gao, Q. 2005. Sequência de inserção bacteriana IS256 como potencial marcador molecular para discriminar cepas invasivas de cepas comensais de Staphylococcus epidermidis. Journal of Hospital Infecção, 61: 342-348. Doi: https:// doi.org/10.1016/j.jhin.2005.04.017.
International Working Group on the Classification of Staphylococcal Cassette Chromosome Elements (IWG-SCC). 2009. Classification of staphylococcal cassette chromosome mec (SCCmec): guidelines for reporting novel SCCmec elements. Antimicrobial agents and chemotherapy, 53: 4961-4967. Doi: 10.1128 / AAC.00579-09.

Mehndiratta, P. L.; Bhalla, P. 2014. Use of antibiotics in animal agriculture \& emergence of methicillin-resistant Staphylococcus aureus (MRSA) clones: Need to assess the impact on public health. The Indian journal of medical research, 140: 339. Disponível em: https://www.ncbi.nlm. nih.gov/pmc/articles/PMC4248379/.

Melo, D. A. D.; Coelho, I. D. S.; Motta, C. C. D.; Rojas, A. C. C. M.; Dubenczuk, F. C.; Coelho, S. D. M. D. O.; Souza, M. M. S. D. 2014. Impairments of mecA gene detection in bovine Staphylococcus spp. Brazilian Journal of Microbiology, 45: 1075-1082. Doi: https:// doi.org/10.1590/S1517-83822014000300041.

Mendonça, E. C.; Marques, V. F.; Melo, D. A.; Alencar, T. A.; Coelho, I. D. S.; Coelho, S. M.; Souza, M. 2012. Caracterização fenogenotípica da resistência antimicrobiana em Staphylococcus spp. isolados de mastite bovina. Pesquisa Veterinária Brasileira, 32: 859-864. Doi: https://doi. org/10.1590/S0100-736X2012000900008.

Moritz, F; Moritz, C. M. F. 2016. Resistência aos antimicrobianos em Staphylococcus spp. associados à mastite bovina. Revista De Ciência Veterinária E Saúde Pública, 3: 132-136. Doi: https://doi.org/10.4025/ revcivet.v3i2.34435.

Olsen, J. E.; Christensen, H.; Aarestrup, F. M. 2006. Diversity and evolution of blaZ from Staphylococcus aureus and coagulase-negative staphylococci. Journal of Antimicrobial Chemotherapy, 57: 450-460. Doi: https://doi.org/10.1093/jac/dki492.

Pantosti; A. 2012. Methicillin-resistant Staphylococcus aureus associated with animals and its relevance to human health. Frontiers in microbiology; 3: 127. Doi: https://doi.org/10.3389/fmicb.2012.00127.

Paterson, G. K.; Harrison, E. M.; Holmes, M. A. 2014. The emergence of mecC methicillin-resistant Staphylococcus aureus. Trends in microbiology, 22: 42-47. Doi: 10.1016 / j.tim.2013.11.003.

Qu, Y.; Zhao, H.; Nobrega, D. B.; Cobo, E. R.; Han, B.; Zhao, Z.; Shumei, L.; Mengyue, L.; Herman, W. B.; Gao, J. 2019. Molecular epidemiology and distribution of antimicrobial resistance genes of Staphylococcus species isolated from Chinese dairy cows with clinical mastitis. Journal of dairy Science, 102: 1571-1583. Doi: https://doi.org/10.3168/jds.201815136.

Rabelo, M. A.; Bezerra Neto, A. M.; Loibman, S. O.; da Costa Lima, J. L.; Ferreira; E. L., Leal, N. C.; Maciel, M. A. V. 2014. The occurrence and dissemination of methicillin and vancomycin-resistant Staphylococcus in samples from patients and health professionals of a university hospital in Recife, State of Pernambuco, Brazil. Revista da Sociedade Brasileira de Medicina Tropical, 47: 437-446. Doi: https://doi.org/10.1590/00378682-0071-2014.

Rahi, A.; Kazemeini, H.; Jafariaskari, S.; Seif, A.; Hosseini, S.; Dehkordi, F. S. 2020. Avaliação genotípica e fenotípica da resistência a antibióticos e perfil do cromossomo mec cassete estafilocócico no Staphylococcus aureus resistente à meticilina recuperado do leite cru. Infecção e resistência a medicamentos, 13: 273. Doi: https://doi.org/10.2147/IDR.S229499. 
Ruegg, P. L.; Oliveira, L.; Jin ,W.; Okwumabua, O.; 2015 Phenotypic antimicrobial susceptibility and occurrence of selected resistance genes in gram-positive mastitis pathogens isolated from Wisconsin dairy cows. Journal of dairy Science, 98:4521-34. Doi: https://doi.org/10.3168/ jds.2014-9137.

Sales, L. M.; Silva, T. M. Staphylococcus aureus meticilina resistente: um desafio para a saúde pública. 2012. Acta Biomedica Brasiliensia, 3: 1-13. Disponível em: https://actabiomedica.com.br/index.php/ acta/article/view/31.

Schnitt, A.; Tenhagen, B. A. 2019. Risk Factors for the Occurrence of Methicillin-Resistant Staphylococcus aureus in Dairy Herds: An Update. Food borne pathogens and disease. Doi: https://doi. org/10.1089/fpd.2019.2638.

Sheet, O. H.; Grabowski, N. T.; Klein, G.; Reich, F.; Abdulmawjood, A. 2019. Characterisation of mecA gene negative Staphylococcus aureus isolated from bovine mastitis milk from Northern Germany. Folia Microbiologica, 64: 845-855. Doi: 10.1007 / s12223-019-00698-z.

Silva, J. G.; Alcântara, A. M.; Mota, R. A. 2018. Mastite bovina causada por Staphylococcus spp. resistentes à meticilina: revisão de literatura. Pesquisa Veterinária Brasileira, 38: 223-228. Doi: https:// doi.org/10.1590/1678-5150-pvb-4996.

Silva, N. C. C.; Guimarães, F. F.; Manzi, M. P.; Budri, P. E.; Gómez-Sanz, E.; Benito, D.; Langoni, H.; Rall, V. L. M.;Torres, C. 2013. Molecular characterization and clonal diversity of methicillin-susceptible Staphylococcus aureus in milk of cows with mastitis in Brazil. Journal of dairy Science, 96: 6856-6862. Doi: https://doi.org/10.3168/jds.20136719.
Siqueira, A. K.; Salerno, T.; Lara, G. H. B.; Condas, L. A. Z.; Pereira, V. C.; Riboli, D. F. M.; Listoni, F. J. P.; Silva. A. V.; Leite, D. S.; Cunha, M. L. R. S.; Ribeiro, M. G. 2017. Enterotoxin genes, multidrug resistance, and molecular typing of Staphylococcus spp. isolated from organic bovine milk. Brazilian Journal of Veterinary Research and Animal Science, 54: 81-87. Disponível em: https://doi.org/10.11606/issn.1678-4456. bjvras.2017.109171.

Song, M.; He, Y.; Zhou, H.; Zhang, Y.; Li, X.; Yu, Y. 2016. Combined analysis of DNA methylome and transcriptome reveal novel candidate genes with susceptibility to bovine Staphylococcus aureus subclinical mastitis. Scientific reports, 6: 1-15. Doi: https://doi.org/10.1038/ srep29390.

Souza; G. A. A D.; Almeida, A. C.; Souza Xavier, M. A.; Silva, L. M. V.; Souza, C. N.; Sanglard, D. A. Oliveira Xavier, A. R. E. 2019. Characterization and molecular epidemiology of Staphylococcus aureus strains resistant to beta-lactams isolated from the milk of cows diagnosed with subclinical mastitis. Veterinary World, 12:1931. Doi: $10.14202 /$ vetworld.2019.1931-1939.

Xavier, A. R. E. O.; Almeida, A. C.; Souza, C. N.; Silva, L. M. V.; Ruas, A. X. A.; Sanglard, D. A.; Júnior, A. F. M.; Oliveira, A. M. E.; Xavier, M. A. S. 2017a. Phenotypic and genotypic characterization of Staphylococcus aureus isolates in milk from flocks diagnosed with subclinical mastitis. Genetics and Molecular Research, 16: 1-11. Doi: http://dx.doi.org/10.4238/gmr16029709.

Xavier, A. R. E. O.; Lima, E. R.; Oliveira, A. M. E.; Cardoso, L.; Santos, J.; Cangussu, C. H. C.; Santos, J. Cardoso, L.; Oliveira, A. M. E.; Lima, E. R.; Xavier, M. A. S. 2017b. Genetic diversity of Bacillussp producers of amylase isolated from the soil. Genetics and Molecular Research, 16. Doi: 10.4238 / gmr16039771. 